\title{
A call to arms: a perspective on safe general surgery in Singapore during the COVID-19 pandemic
}

\author{
Min-Hoe $\underline{\text { Chew }}{ }^{1}$, MBBS, fRCSEd, Frederick $H \underline{K o h}^{1}$, MBBS, FRCSEd, Kheng Hong $\underline{\mathrm{Ng}^{2}}$, MBBS, fRCSEd
}

\section{INTRODUCTION}

The coronavirus disease 2019 (COVID-19) pandemic crisis has reached a critical juncture. At the time of writing, the World Health Organization has reported more than 750,800 cases and 36,405 deaths. ${ }^{(1)}$ The speed of disease spread has been staggering. While it took three months to reach the first 100,000 cases, it took only 12 days to reach the next 100,000 and less than five days for the next 200,000 cases. ${ }^{(2)}$

The first imported case of COVID-19 was reported in Singapore on 23 January 2020. ${ }^{(3)}$ Local transmission was confirmed on 4 February 2020 and the Disease Outbreak Response System Condition (DORSCON) status was raised to Orange on 7 February $2020 .{ }^{(4)}$ DORSCON is a colour-coded framework that defines the infectious disease condition as well as the measures taken to reduce disease transmission in Singapore. ${ }^{(5)}$ As of 29 March 2020, there were 844 cases in Singapore and three deaths. ${ }^{(2)}$

Surgical safety has fallen under the spotlight as the pandemic shifted its epicentre from China to Europe and the United States of America. ${ }^{(1)}$ Surgeons are being called upon to cancel elective procedures and focus on maintaining only emergency operations and elective cancer surgeries, ${ }^{(6-9)}$ as recommended by guidelines based on experiences in Italy ${ }^{(10)}$ and China. ${ }^{(11)}$ Decisions to persist with elective surgeries in some countries have met with opposition and criticism. ${ }^{(12)}$ Concerns are mainly centred on the risk of viral transmission during surgery. To date, the evidence is clear that COVID-19 is transmitted via close contact through respiratory droplets and fomites. ${ }^{(13-15)}$ The risk of airborne transmission exists and is highest during aerosol-generating clinical procedures such as intubation, extubation, laparoscopy and endoscopy. These procedures present inherent risks to anaesthesiologists, surgeons and operating nursing staff, or any unsuspecting person within the operating room $(\mathrm{OR})$.

Various international bodies have published recommendations. Although the evidence is not strong, the human immunodeficiency virus, Corynebacterium and human papillomavirus has been detected in surgical smoke. ${ }^{(16,17)}$ The use of laparoscopic ultrasonic scalpels and diathermy also produces a far higher concentration of surgical smoke than open surgery due to low gas mobility in the pneumoperitoneum. Furthermore, viral cellular components are not deactivated effectively because of low temperatures. ${ }^{(10)}$ The risk to the surgeon is thus theoretically higher, especially during the evacuation of gas, which can happen during specimen extraction, venting of smoke via trocars during surgery to improve visualisation, or unintended gas leakages due to poor seals between trocars and the abdominal wall. The second concern is the utility of valuable personal protective equipment (PPE). There have been critical shortages of PPE worldwide. ${ }^{(18)}$ Graphic images of healthcare workers (HCWs) using self-made PPE from plastic or garbage bags have gone viral, as well as complaints on social media about the lack of availability of PPE or restrictions on the use of N95 respirators, some of which were posted by HCWs from respected medical systems.

\section{THE SITUATION IN SINGAPORE}

Our experience with the severe acute respiratory syndrome (SARS) coronavirus in 2003 has been critical to the current battle against COVID-19. During SARS, we witnessed high rates of viral transmission among HCWs. In Singapore, $41 \%$ of 238 SARS patients were HCWs, and there were five fatalities. ${ }^{(19)}$ The disease was only contained with strict adherence to infection control practices. Two hospitals reported changes to their practices in the OR. ${ }^{(20,21)}$ This included reorganisation and physical modification of the OR, infection control practices and staff training on personal protection. Our local experience of surgeries during SARS consisted of 41 procedures performed, of which 15 were tracheostomies (high-risk patients). With these measures in place, there was zero transmission although $124 \mathrm{HCWs}$ had direct contact with SARS patients. ${ }^{(20)}$

Singapore's response to the COVID-19 outbreak has been rapid. In various hospitals, clinical stratification with screening procedures was implemented to ensure that elective patient care could safely continue. These procedures evolved as the disease outbreak situation worsened. All patients were required to submit a health and travel declaration, and those with a history of travel to affected areas or flu-like symptoms were advised to postpone surgery. All hospitals installed thermal scanners to detect possible symptomatic cases on the day of admission.

For departments, staff segregation was implemented to ensure business continuity, so that departments would remain functional should anyone fall ill. Stepwise reduction of elective work was implemented in public hospitals to allow deployment of manpower to frontline departments such as emergency departments and intensive care units.

For surgeons, refresher training was conducted on the use of PPE. This included N95 mask fitting as well as training on powered air-purifying respirators (PAPRs). All staff were also

${ }^{1}$ Department of General Surgery, Sengkang General Hospital, ${ }^{2}$ Gleneagles Hospital, Singapore

Correspondence: Adj A/Prof Chew Min-Hoe, Head and Senior Consultant, Department of General Surgery, Sengkang General Hospital, 110 Sengkang East Way, Singapore 544886. chew.min.hoe@singhealth.com.sg 
compliant to twice-daily temperature monitoring. In some hospitals, temperatures could be entered into Web-based forms via personal smartphones. Staff who developed symptoms were to seek a medical consultation within the hospital staff clinic. This enabled symptomatic staff to be identified promptly.

In various hospitals, detailed workflows were created on how to operate on COVID-19 cases, including suspect cases who were pending swab test results. ${ }^{(22,23)}$ Patients who were operated on were emergency cases who required time-sensitive surgery (e.g. limb salvage) or very sick patients whose outcomes could be compromised while waiting for swab test results. For some hospitals, alternate OR complexes separated from the main OR were identified for COVID-19 patients, thus avoiding contamination of other ORs. ${ }^{(22)}$ Some newer hospitals have negative pressure ORs to prevent dissemination of the virus beyond the OR.

In many ORs, there is an average of 15-40 air exchanges per hour. It has been suggested that it may take 14-18 minutes to ensure clean OR air for the next patient or staff. ${ }^{(24)}$ The first author's hospital (Sengkang General Hospital) has created an intubationextubation protocol that has been in practice since the COVID-19 outbreak. In this protocol, a five-minute pause is mandated during intubation and extubation, with only the anaesthetists and assistant donning full PPE in the OR. This ensures that at least two gas exchanges of the OR are taken and enhances safety in the very unlikely chance that the surgeons are operating on an undiagnosed COVID-19 case. To address concerns in laparoscopy, an additional 15 minutes have been factored in, which commences on evacuation of the pneumoperitoneum. This allows a complete 20 minutes of air exchange on completion of surgery and extubation (Box 1).

\section{DISCUSSION}

The COVID-19 pandemic outbreak has shown no signs of abating. Cautious guidelines have been proposed in the Western surgical community, which anticipated that cases would 'skyrocket'. ${ }^{(8,9)}$ Resource preservation and surgeon safety have been the priority in these recommendations.

In Singapore, the situation is quite different. National detection and containment strategies with aggressive contact tracing $^{(25)}$ have kept the disease outbreak relatively contained. Measures in hospitals to ensure clinical stratification and judicious postponement of procedures; staff segregation in general surgical departments to maintain business continuity and provide optimal surgical care; and efforts by surgeons to take individual responsibility have allowed for a safe environment to continue elective cases. There has been sufficient PPE as well.

Nonetheless, with the sharp rise in imported cases in March 2020, it is imperative that there is heightened alertness to the dangers of viral transmission during surgery. Similarly, resource allocation and preservation still remains a major consideration to facilitate deployment of manpower and resources to the front line if required, such as to the emergency department and intensive care unit. General surgeons in the pandemic phase of the COVID-19 outbreak should consider the following principles:

\section{Box 1. Suggested intubation-extubation protocol during a} pandemic:

1. Intubation is to be performed only with one anaesthetist, surgical doctor and anaesthetic unit nurse present in the operating room (OR). (Note: surgeon to wear N95 if assisting in intubation.)

2. All personnel in the OR during intubation should wear N95 and eye protection.

3. Surgical team completes 'sign-in', then vacates the OR; only the anaesthetic team is to remain in the OR during the intubation/aerosol-generating procedure.

4. Anaesthetist announces 'Clear OR, intubation now' to vacate personnel from the OR during intubation. No vendors are allowed in the OR until support is required.

5. For all non-laparoscopic surgeries: the surgical team must wait five minutes after intubation to allow clean scrub of air. (Note: the OR performs 25 cycles of air exchange per hour, 100\% clean air will be circulated in OR within 2.5 minutes; the five minutes' allowance will ensure that two cycles of air exchange are performed.) Operation is to proceed with surgical masks.

6. Extubation is to be done only with the anaesthetist team in the OR. Anaesthetist is to announce 'Clear OR, extubation now' to initiate extubation. The rest of the surgical team vacates the $O R$.

7. Anaesthetist announces 'Extubation complete' after the patient is fully extubated. The rest of the surgical team members are to wait five minutes after extubation before returning to the OR.

8. For all elective and emergency laparoscopic surgeries: all staff in laparoscopic surgeries are to be in N95 throughout the case and can remain in the OR during intubation and extubation.

9. Doors (OR main door and scrub door) are locked at induction of anaesthesia and will remain so until 15 minutes after deflation of pneumoperitoneum. Access to the induction room is permitted.

10. Upon final deflation of pneumoperitoneum, circulating nurse starts the timer countdown for 15 minutes. Doors are to remain closed until the 15 minutes is up.

11. At extubation, staff in $\mathrm{N} 95$ can remain. OR doors are to remain closed until five minutes after the end of extubation.

1. All surgical patients must undergo mandatory pre-surgery screening to determine their risk of COVID-19 infection. Besides travel history, information collected could include contact with those on home quarantine or stay home notices. Postponement can be considered.

2. Elective surgery should only be performed for diseases that are time-sensitive (e.g. cancers, limb salvage, and symptomatic benign disease with risk of infection or deterioration).

3. Emergency surgery should be performed promptly but only with adequate staffing and PPE.

4. Aerosol-generating procedures such as laparoscopy and endoscopy can continue, but additional measures should be considered. Surgeons and OR/endoscopy staff should be in full PPE, including N95 respirators or PAPRs. Adequate air-exchange times in the OR should be considered if laparoscopy surgery is performed. Minimal staff should be present in the OR during laparoscopic surgery.

5. Be mindful of the consumption of PPE. Risk stratification of patients is important to avoid overdepletion of PPE supplies. 
6. Surgical policies may have to change as the pandemic disease burden evolves.

While the above measures are by no means exhaustive, these guiding principles help to align some of the perspectives that all general surgeons can adopt in the coming weeks to months. Our fight against the COVID-19 pandemic is just beginning, and all surgeons must be fully ready for the difficult period ahead.

\section{REFERENCES}

1. World Health Organization. Coronavirus disease 2019 (COVID-19). Situation Report 69. Available at: https:/www.who.int/docs/default-source/coronaviruse/ situation-reports/20200331-sitrep-71-covid-19.pdf?sfvrsn=4360e92b_6. Accessed March 31, 2020.

2. John Hopkins University and Medicine Coronavirus Resource Center Coronavirus COVID-19 global cases. Available at: https://coronavirus.jhu.edu/ map.html. Accessed March 30, 2020.

3. Abdullah Z, Salamat H. Singapore confirms first case of Wuhan virus. In ChannelNewsAsia [online]. Available at: https://www.channelnewsasia. com/news/singapore/wuhan-virus-pneumonia-singapore-confirms-firstcase-12312860. Accessed March 30, 2020.

4. Ministry of Health, Singapore. Risk assessment raised to DORSCON Orange Available at: https://www.moh.gov.sg/news-highlights/details/risk-assessmentraised-to-dorscon-orange. Accessed March 30, 2020.

5. What do the different DORSCON levels mean? In: gov.sg [online]. Available at: https://www.gov.sg/article/what-do-the-different-dorscon-levels-mean. Accessed March 30, 2020.

6. Society of American Gastrointestinal and Endoscopic Surgeons. SAGES and EAES recommendations regarding surgical response to COVID-19 cases. Available at: https://www.sages.org/recommendations-surgical-response-covid-19/. Accessed March 30, 2020.

7. American College of Gastroenterology. Joint GI Society message on COVID-19. Available at: https://gi.org/2020/03/15/joint-gi-society-message-on-covid-19/. Accessed March 30, 2020.

8. Royal College of Surgeons. Guidance for surgeons working during the COVID-19 pandemic. Available at: https://www.rcseng.ac.uk/coronavirus/joint-guidancefor-surgeons-v1/. Accessed March 30, 2020

9. American College of Surgeons. COVID-19: elective case triage guidelines for surgical care. Available at: https://www.facs.org/covid-19/clinical-guidance/ elective-case. Accessed March 30, 2020.

10. Spinelli A, Pellino G. COVID-19 pandemic: perspectives in an unfolding crisis. Br J Surg 2020; 107:785-7.
11. Zheng $\mathrm{MH}$, Boni $\mathrm{L}$, Fingerhut $\mathrm{A}$. Minimally invasive surgery and the novel coronavirus outbreak: lessons learnt in China and Italy. Ann Surg 2020; 272:e5-6.

12. Royal Australasian College of Surgeons. Medical colleges express grave concerns at Federal Government move to extend private hospital elective surgery deadline. Available at: https://www.surgeons.org/news/media-releases/ medical-colleges-express-grave-concerns-at-federal-government-move-toextend-private-hospital-elective-surgery-deadline. Accessed March 30, 2020.

13. Ong SWX, Tan YK, Chia PY, et al. Air, surface environmental, and personal protective equipment contamination by severe acute respiratory syndrome coronavirus 2 (SARS-CoV-2) from a symptomatic patient. JAMA 2020; 323:1610-2.

14. Huang C, Wang Y, Li X, et al. Clinical features of patients infected with 2019 novel coronavirus in Wuhan, China. Lancet 2020; 395:497-506.

15. Li Q, Guan X, Wu P, et al. Early transmission dynamics in Wuhan, China, of novel coronavirus-infected pneumonia. N Engl J Med 2020; 382:1199-207.

16. Hensman C, Baty D, Willis RG, Cuschieri A. Chemical composition of smoke produced by high-frequency electrosurgery in a closed gaseous environment. Surg Endosc 1998; 12:1017-9.

17. Johnson GK, Robinson WS. Human immunodeficiency virus-1 (HIV-1) in the vapors of surgical power instruments. J Med Virol 1991; 33:47-50.

18. World Health Organization. WHO Director-General's opening remarks at the media briefing on COVID-19 - 27 March 2020. Available at: https://www.who. int/dg/speeches/detail/who-director-general-s-opening-remarks-at-the-mediabriefing-on-covid-19---27-march-2020. Accessed March 30, 2020.

19. Ministry of Health, Singapore. Communicable disease surveillance in Singapore 2003. Special feature: severe acute respiratory syndrome (SARS). Available at: https://www.moh.gov.sg/docs/librariesprovider5/resources-statistics/reports/ special_feature_sars.pdf. Accessed March 30, 2020.

20. Chee VW, Khoo ML, Lee SF, Lai YC, Chin NM. Infection control measures for operative procedures in severe acute respiratory syndrome-related patients. Anesthesiology 2004; 100:1394-8.

21. Tank TK. How severe acute respiratory syndrome (SARS) affected the department of anaesthesia at Singapore General Hospital. Anaesth Intensive Care 2004; 32:394-400

22. Ti LK, Ang LS, Foong TW, Ng BSW. What we do when a COVID-19 patient needs an operation: operating room preparation and guidance. Can J Anaesth 2020; 67:756-8.

23. Wong J, Goh QY, Tan Z, et al. Preparing for a COVID-19 pandemic: a review of operating room outbreak response measures in a large tertiary hospital in Singapore. Can J Anaesth 2020; 67:732-45.

24. Centers for Diseases Control and Prevention. CDC infection control guidelines and guidance library. Available at: https://www.cdc.gov/infectioncontrol/ guidelines/index.html. Accessed March 30, 2020

25. Wong JEL, Leo YS, Tan CC. COVID-19 in Singapore-current experience: critical global issues that require attention and action. JAMA 2020 Feb 20. https://doi. org/10.1001/jama.2020.2467. [Epub ahead of print] 